\title{
Antidopaminergic medication in healthy subjects provokes subjective and objective mental impairments tightly correlated with perturbation of biogenic monoamine metabolism and prolactin secretion
}

This article was published in the following Dove Press journal: Neuropsychiatric Disease and Treatment

\section{Tanja Veselinović, $, 1,2$ Ingo Vernaleken, ${ }^{1,2}$ Paul Cumming, ${ }^{3,4}$ Uwe Henning, ${ }^{5}$ Lina Winkler, ${ }^{1,2}$ Peter Kaleta, ${ }^{1,2}$ Michael Paulzen, ${ }^{1,2}$ Christian Luckhaus, ${ }^{6}$ Gerhard Gründer ${ }^{1,2,7}$ \\ 'Department of Psychiatry, Psychotherapy, and Psychosomatics, Faculty of Medicine, RWTH Aachen University, Aachen, ${ }^{2}$ Translational Brain Medicine, Jülich Aachen Research Alliance (JARA), Jülich, Germany; ${ }^{3} \mathrm{HBI}$, School of Psychology and Counselling, Queensland University of Technology, ${ }^{4} \mathrm{QIMR}$ Berghofer Institute, Brisbane, Australia; ${ }^{5}$ Neurobiochemical Research Unit, Department of Psychiatry, Heinrich Heine University, Düsseldorf, ' ${ }^{\circ} \mathrm{WWL}$ University Hospital Bochum, Department of Psychiatry, Division of Cognitive Neuropsychiatry and Psychiatric Preventive Medicine, Ruhr University Bochum, Bochum, ${ }^{7}$ Department of Molecular Neuroimaging, Central Institute of Mental Health, Mannheim, Germany}

Correspondence: Tanja Veselinović Department of Psychiatry, Psychotherapy, and Psychosomatics, Faculty of Medicine, RWTH Aachen University, 30 Pauwelsstrasse, Aachen 52074,

Germany

Tel +4924 I803 5893

Fax +4924I808940I

Email tveselinovic@ukaachen.de
Objectives: Off-label prescription of antipsychotics to patients without psychotic symptoms has become a routine matter for many psychiatrists and also some general practitioners. Nonetheless, little is known about the possibly detrimental effects of antidopaminergic medications on general psychopathology, subjective mental state, or a possible association with physiological parameters in nonpsychotic individuals.

Methods: In this randomized, single-blinded study, groups of healthy volunteers $(n=18)$ received low doses of reserpine, aripiprazole, haloperidol, or placebo on 7 successive days. Relevant physiological parameters (plasma prolactin, concentrations of catecholamine metabolites in plasma, and 24-hour urine) and each subject's mental state (Positive and Negative Syndrome Scale, Hamilton Rating Scale for Depression, visual analogue scale, Beck Depression Inventory II) were assessed at the start and end of the trial.

Results: Of the three active treatments, only reserpine caused a significant increase in some plasma- and urine-catecholamine metabolites, but all three medications evoked objective and subjective changes in general psychopathology scores, which correlated with individual increases in plasma homovanillic acid concentrations. Both objective and subjective impairments were significantly more pronounced in the subgroup with greatest increase of plasma prolactin. Subjects experiencing the most pronounced side effects under haloperidol, which compelled them to drop out, showed significantly higher prolactin concentration increases than those who tolerated haloperidol well.

Conclusion: We found consistent associations between altered markers of dopamine transmission and several objective and subjective mental impairments in healthy volunteers after 1 week's treatment with antidopaminergic medications. These findings should draw attention to a more intensive risk-benefit evaluation in cases of off-label prescription of antipsychotic medications.

Keywords: catecholamine metabolites, HVA, prolactin, dopamine, reserpine, aripiprazole, haloperidol, off-label prescription

\section{Introduction}

Off-label prescription of psychoactive drugs is emerging as a widespread phenomenon in many countries. ${ }^{1-4}$ Whereas antipsychotic medications are indicated for the alleviation of psychotic symptoms of schizophrenia, mood disorders, and delirium, $\sim 20 \%$ 
of all antipsychotic prescriptions in a US nationally representative survey were off-label. ${ }^{4}$ The most common off-label indications are for relief of insomnia, pain, and agitation. ${ }^{5,6}$ While effective antipsychotic medications are generally characterized as having antidopaminergic actions, there has been little information about the iatrogenic physiological and psychopathological perturbations provoked by off-label administration of antidopaminergic medication in patients without psychotic disorders.

Central dopaminergic transmission is the primary target of antipsychotic medications. Dopamine in turn acts as a key neurotransmitter in the brain, with a pronounced regulatory role for motor, limbic, motivational, and cognitive functions. ${ }^{7}$ Consequently, some recent investigations have emphasized a negative impact of antipsychotics on cognitive function in patients with schizophrenia, ${ }^{8-12}$ contrary to some older reports of their small beneficial cognitive effects. ${ }^{13-15}$

While molecular imaging by positron-emission tomography gives a direct index of central dopaminergic pathways, ${ }^{16}$ measurements of biogenic amine metabolites in blood and urine have for more than 50 years served as a surrogate index of central neurotransmitter metabolism. The main metabolites of interest in such examinations have been the serotonin metabolite 5-hydroxyindoleacetic acid (5-HIAA), the central noradrenaline metabolite 3-methoxy-4-hydroxyphenylglycol (MHPG), the peripheral noradrenaline metabolite vanillylmandelic acid (VMA), and especially the dopamine metabolite homovanillic acid (HVA). The plasma concentration of the latter metabolite (pHVA) is considered to bear a particular relation with the turnover of brain dopamine in experimental animals and humans. ${ }^{17-21}$ These studies have shown that $11 \%-35 \%$ pHVA originates from the brain, whereas the remainder is derived from catecholamine metabolism in sympathetic nerves and the adrenal gland. Formed from brain dopamine by the successive actions of catechol- $O$-methyltransferase and monoamine oxidase, interstitial HVA diffuses from the brain by a probenecidsensitive process, enters the circulation, and ultimately passes into the urine. ${ }^{16}$

The link between pHVA and central dopamine transmission has motivated a large body of clinical research, most of which has been conducted in patients with schizophrenia. The results have been somewhat incongruent, ${ }^{22-30}$ no doubt reflecting the clinical heterogeneity of schizophrenia, duration of illness, the mixed origin of pHVA, and effects of previous pharmacological treatments. Overall, these findings indicate a considerable association between plasmacatecholamine metabolites, as an indirect indicator of brain dopamine activity, and acute and delayed clinical responses to antipsychotic treatment.

However, relatively little is known about the corresponding associations in healthy individuals, or indeed in patients receiving off-label antidopaminergic treatments. In one of the few such studies, a positive correlation between age and pHVA levels in healthy men and women was reported, ${ }^{31}$ consistent with findings of age-dependent increases in brain dopamine turnover to positron-emission tomography. ${ }^{32}$ Another plasma-metabolite study reported an inverse correlation between $\mathrm{pHVA}$ and history of childhood trauma in adults with personality disorder and healthy controls, ${ }^{33}$ concurring with results of a similar study of 5-HIAA and HVA in cerebrospinal fluid, ${ }^{34}$ which is more closely reflective of central neurotransmitter metabolism. Still others observed an acute reduction in pHVA in healthy individuals subjected to experimental stress. ${ }^{35}$

Another physiological parameter with high sensitivity to treatment with antipsychotics is the hormone prolactin. Its release from lactotroph cells of the anterior pituitary gland is tightly regulated by tonic dopaminergic inhibition. ${ }^{36}$ Indeed, the hypothalamic tuberoinfundibular dopaminergic system is considered the most important regulator of prolactin secretion. ${ }^{37}$ Treatment with antipsychotic medication causes disinhibition of lactotrophs and is indeed the common cause of pharmacologically induced hyperprolactinemia. ${ }^{38}$ This adverse side effect has been well described for firstgeneration ${ }^{39}$ and second-generation antipsychotics. ${ }^{40}$ As such, prolactin responses provide another approach for assessing pharmacodynamic response to antipsychotic medications. Decreased plasma prolactin is a surrogate for brain dopamine receptor-agonist occupancy in Parkinson's disease patients ${ }^{41}$ and there is an association between prolactin increases and cognitive effects of haloperidol in healthy volunteers, ${ }^{42}$ but there are barely any other reports in the context of off-label medication with antipsychotics.

Given the paucity of information about cognitive and physiological effects of off-label use of antidopaminergics, we undertook to study the relationship between plasma (pHVA, p5-HIAA, pMHPG) and urine metabolites (uHVA, u5-HIAA, uVMA) and prolactin levels in relation to general psychopathological and subjective conditions, particularly related to perceived cognitive interferences in healthy volunteers treated for 7 days with low doses of three antidopaminergic medications with entirely different mechanism of action: reserpine, aripiprazole, and haloperidol. We hypothesized that iatrogenic psychopathological and subjective impairments in healthy volunteers would be proportional 
to the biochemically indicated antidopaminergic effect of each substance.

\section{Methods}

\section{Experimental procedures}

This single-blind, randomized, placebo-controlled, parallelgroup study was conducted at the Department of Psychiatry, Psychotherapy, and Psychosomatics of University Hospital RWTH Aachen, Aachen, Germany. The study was approved by the German Federal Institute for Drugs and Medical Devices (BfArM) and the ethics committee responsible from RWTH Aachen University, and was conducted in accordance with the ethical standards laid down in the Helsinki Declaration of 1975, as revised in 1983. All participants gave written informed consent after the study protocol had been explained to them in detail.

\section{Subjects}

Healthy subjects aged $18-55$ years were recruited through advertisement. Prior to inclusion, they were screened for psychiatric history using the Structured Clinical Interview for DSM-IV, ${ }^{43}$ and had a physical examination. Exclusion criteria comprised presence or history of mental disorders, use of psychotropic drugs, and nicotine abuse or dependence, as well as presence or history of any significant medical or neurological disorder (specifically hypotension, long QT syndrome, cardiac arrhythmia, regular use of drugs causing QT prolongation on electrocardiography, peptic ulcer, ulcerative colitis, paralytic ileus, galactose intolerance, lactase deficit, glucose-galactose malabsorption, epilepsy, and reduced renal or liver function). All subjects were required to have a negative urine-toxicology screening before participating in the study. Electrocardiography, electroencephalography, routine laboratory parameters, and physical and neurological examination had to be without pathological findings. Participants were instructed to abstain from alcohol and operation of a vehicle during their participation in the study part. They affirmed not taking part in concomitant clinical studies.
For female participants, a negative pregnancy test and secure contraception were required. Females without regular hormonal contraception could participate only when in the follicular phase of the menstrual cycle. Women using contraception were included in the period of stable intake of combined oral contraceptive pills or retention of a vaginal ring. A total of 72 volunteers (mean age $26.3 \pm 6.2$ years) were included, of which 34 males (mean age $24.9 \pm 4$, range 22-43 years) and 38 females (mean age 27.5 \pm 7.5 , range 20-50 years). Participants were randomly assigned to treatment groups in a single-blind procedure (unaware which drug they receive) with control for matching of sex and demographics, as presented in Table 1.

\section{Antidopaminergic interventions}

Participants were randomly assigned to one of four groups of 18 each, and received either placebo or one of the three antidopaminergic substances orally. Three antipsychotic substances with entirely different mechanisms of action were investigated: aripiprazole, haloperidol, and reserpine. To ensure tolerability, doses were raised gradually (aripiprazole, first day $5 \mathrm{mg}$, second day $10 \mathrm{mg}$, third-seventh day $15 \mathrm{mg}$; haloperidol, first day $1 \mathrm{mg}$, second day $2 \mathrm{mg}$, third-seventh day $3 \mathrm{mg}$; reserpine, first day $0.25 \mathrm{mg}$, second day $0.5 \mathrm{mg}$, third-seventh day $1 \mathrm{mg}$ ), thus obtaining doses in the range employed for psychosis.

Aripiprazole is a relatively new antipsychotic medication, characterized by its partial agonism at several G-proteincoupled receptors (especially dopamine $\mathrm{D}_{2}, \mathrm{D}_{3}$ and $\mathrm{D}_{4}$ and serotonin $5 \mathrm{HT}_{1 \mathrm{~A}}, 5 \mathrm{HT}_{2 \mathrm{C}}$, and $5 \mathrm{HT}_{7}$ ) and its antagonistic action at other receptors (especially $5 \mathrm{HT}_{2 \mathrm{~A}}$, and $\left.5 \mathrm{HT}_{6}\right)^{44}$ Haloperidol is the prototypic first-generation butyrophenone antagonist of dopamine $\mathrm{D}_{2}$ and $\mathrm{D}_{3}$ receptors and negligible binding to other receptors, with the exception of $\alpha_{1 \mathrm{~B}}$-adrenergic receptors. ${ }^{45}$ Reserpine, an alkaloid from Rauwolfia serpentina, was introduced into the Western pharmacopoeia in $1952^{46}$ for treatment of psychosis. Reserpine acts by blocking the vesicular monoamine transporter type 2

Table I Demographic data concerning age, sex proportion, BMI, and education in the different groups

\begin{tabular}{|c|c|c|c|c|c|c|}
\hline $\begin{array}{l}\text { Treatment } \\
\text { group }\end{array}$ & $\mathbf{n}$ & $\begin{array}{l}\text { Age } \\
(\text { mean } \pm \text { SD) }\end{array}$ & $\begin{array}{l}\text { Female:male } \\
\text { proportion }\end{array}$ & BMI & $\begin{array}{l}\text { Education, years } \\
\text { (mean } \pm \mathrm{SD})\end{array}$ & $\begin{array}{l}\text { Estimated IQ } \\
\text { (mean } \pm \text { SD) }\end{array}$ \\
\hline Aripiprazole & 18 & $25.6 \pm 6.5$ & $\mid \mathrm{I}: 7$ & $24.4 \pm 4.5$ & $15.9 \pm 2.1$ & $123.8 \pm 18.4$ \\
\hline Haloperidol & 18 & $27.2 \pm 6.1$ & $8: 10$ & $23.1 \pm 2.2$ & $15.8 \pm 2.2$ & $115.4 \pm 13.8$ \\
\hline Reserpine & 18 & $27.7 \pm 7.6$ & $8: 10$ & $25.7 \pm 4.3$ & $15.7 \pm 3.6$ & $117.9 \pm 15.3$ \\
\hline Placebo & 18 & $24.6 \pm 3.9$ & $\mathrm{II}: 7$ & $23.2 \pm 2.5$ & $16.8 \pm 2.6$ & $114.3 \pm 14.7$ \\
\hline All & 72 & $26.3 \pm 6.2$ & $38: 34$ & $24.1 \pm 3.6$ & $16.0 \pm 2.7$ & $117.9 \pm 15.8$ \\
\hline
\end{tabular}

Note: For intelligence estimation, the German language multiple-choice test of verbal crystallized premorbid intelligence (Lehrl et al, $\left.1995^{112}\right)$ was used. Abbreviation: BMI, body-mass index. 
in biogenic monoamine neurons, ${ }^{47}$ ultimately causing depletion in intraneuronal dopamine stores. ${ }^{48}$ Placebo was administered to the control group as an inactive white tablet, with dose escalation mimicking the active medications. For randomization, we used a computer-generated random-number list prepared by an investigator with no clinical involvement in the trial. Medications and placebo were administered in the presence of the investigators.

\section{Clinical assessment}

Expert ratings were based on established psychiatric rating scales and clinical interviews, while raters were blind to group affiliation. Depressive symptoms were measured using the Beck Depression Inventory (BDI) ${ }^{49}$ and the 21-item Hamilton Rating Scale for Depression (HRSD). ${ }^{50}$ General psychopathological symptoms were assessed using the Positive and Negative Symptoms Scale (PANSS).${ }^{51}$ For more detailed examination of clinically objective cognitive and affective impairments, depressive and cognitive PANSS components according to the model of Lindenmayer et $\mathrm{al}^{52}$ were included in further analysis. All scales were administered prior to the first drug intake (day 0) and again 24 hours ( \pm 2 hours) after the last drug intake (day 8 ).

In order to record subjective assessment of different aspects of well-being, we applied the visual analogue scale (VAS), which is commonly used for simplified rating of subjective states in research and clinical settings. ${ }^{53}$ By convention, the VAS consists of a straight $100 \mathrm{~mm}$ horizontal line, with end points labeled as the extreme boundaries of the sensation, feeling, or response to be measured. As such, the VAS is scored by measuring the distance in millimeters from one end of the scale to the subject's pencil mark on the line. According to the standardized procedure, we asked participants to score the level of their ability to concentrate, motivation, fatigue, drive, and general well-being between "worst/lowest imaginable" and "highest/best I can imagine" on the straight $100 \mathrm{~mm}$ horizontal line. Scales were also rated on days 0 and 8 .

\section{Prolactin determination}

Blood samples were taken from participants' cubital vein between 11 am and 1:30 pm before the first medication intake and again $24( \pm 2)$ hours after the last treatment. Prolactin concentration was measured as reported previously. ${ }^{54}$

\section{Monoamine metabolite quantification}

Additional $9 \mathrm{~mL}$ venous blood samples were taken on day 1 just prior to first administration of medication and again on day 8 at 24 ( \pm 2 hours) after last drug intake. Subjects had been instructed to follow a diet with low tyramine content (eg, avoiding aged dairy products) beginning at least 5 days prior to the investigation. Blood was immediately centrifuged at 1,850 $\mathrm{g}$ for 10 minutes (Rotixa/RP; Hettich, Vlotho, Germany) and portions of plasma stored at $-80^{\circ} \mathrm{C}$ until analysis, with blinding to origin. After addition of internal standard, the analytes were concentrated by solid-phase extraction (Biotage, Uppsala, Sweden). Quantification of HVA and 5-HIAA was obtained by isocratic reverse-phase high-performance liquid chromatography with an Inertsil ODS analytical column $(250 \times 4.6 \mathrm{~mm}$; GL Sciences, Tokyo, Japan) with electrochemical detection (Decade; Antec Scientific, Zoeterwoude, the Netherlands) according to the method of Gupta and Whelton (1992). ${ }^{113}$ For quantification of MHPG we used a Hypersil ODS column (250×4.6 mm; GL Sciences) with electrochemical detection according to a modification method. ${ }^{55}$ Recovery was $74 \%-80 \%$, with sensitivity of about $1 \mathrm{ng} / \mathrm{mL}$ for $\mathrm{HVA}, \mathrm{MHPH}$, and 5-HIAA. Intra- and interassay coefficients of variation were $7.1 \% / 19.8 \%$ for HVA, $6.9 \% / 18.1 \%$ for MHPG, and $6.0 \% / 7.3 \%$ for 5 -HIAA.

Urine samples (24-hour) were acquired from all participants before first medication and at day 8 . Accumulated urine was collected in a canister (UriSet 24; Sarstedt, Nümbrecht, Germany) containing $9 \mathrm{~mL} \mathrm{20 \%}$ hydrochloric acid for stabilization $(50 \mu \mathrm{L})$. Portions $(20 \mathrm{~mL})$ of urine were analyzed in the central laboratory of University Hospital RWTH Aachen for concentrations of uHVA, uVMA, and u5-HIAA using a commercial kit (ChromSystems, Munich, Germany) entailing a solid-phase extraction cleanup and high-performance liquid chromatography with electrochemical detection. ${ }^{56}$ Interassay coefficients were about $6 \%$ for all three analytes. Only results from participants who completed the protocol (7 days' intake of medication or placebo) were included in the final analyses.

\section{Statistical analysis}

All statistical analyses were conducted using SPSS software (version 20). Normal distributions of the data were obtained after natural logarithmic transformations. The significance of changes and group differences in monoamine metabolite concentrations under the different treatment conditions were assessed by repeated-measures analysis of variance (ANOVA). Student's $t$-test was used for multiple pairwise comparisons, as described in the Results section. Correlations between physiological outcome parameters in the second session and psychopathological scores were explored. 
All tests were two-tailed. An $\alpha$-level of $<0.05$ was considered statistically significant. To accommodate multiple testing, we used $\alpha$-adjustment for Bonferroni correction.

\section{Results}

\section{Completers, dropouts, and side effects}

Seven (four males and three females, mean age $24 \pm 2$ years) of 18 participants (39\%) randomized to the haloperidol group withdrew from the study, due to unpleasant extrapyramidal symptoms. All antidopaminergic interventions caused significant psychopathological changes and cognitive impairments, as described in detail in our previous reports. ${ }^{57,58}$ For technical reasons, some data were missing, resulting in complete data sets across all measures in 62 of the 72 subjects.

\section{Biogenic amine metabolites in plasma and urine}

Mean concentrations of the catecholamine metabolites and the indoleamine metabolite 5-HIAA measured in plasma (pHVA, pHIAA, pMHPG) and urine (uHVA, uHIAA, uVMA) at baseline and day 8 are summarized in Table 2. Repeated-measures ANOVA showed a significant

Table 2 Concentrations of catecholamine metabolites $(\mathrm{ng} / \mathrm{mL})$ in plasma $(\mathrm{P})$ and urine $(\mathrm{u})(\mathrm{ng} /$ day)

\begin{tabular}{|c|c|c|c|c|c|c|}
\hline \multicolumn{7}{|l|}{ Plasma } \\
\hline & \multirow[t]{2}{*}{$\mathbf{n}$} & \multirow{2}{*}{$\frac{\text { Day I }}{\text { pHVA }}$} & \multirow{2}{*}{$\frac{\text { Day } 8}{\text { pHVA }}$} & \multirow[t]{2}{*}{$\Delta \%$ pHVA } & \multirow[t]{2}{*}{ RM ANOVA, time $\times$ group } & \multirow[t]{2}{*}{ Post hoc } \\
\hline & & & & & & \\
\hline Placebo & 18 & $13.84 \pm 6.1$ & $14.24 \pm 6$ & $2.2 \pm 6.8$ & $F_{3,61}=0.45, P=0.717$ & NS \\
\hline Aripiprazole & 18 & $16.73 \pm 5.93$ & $16.45 \pm 5.24$ & $-1.7 \pm 11.6$ & & \\
\hline Haloperidol & 11 & $|3.5| \pm 5.4$ & $|5.2| \pm 4.3$ & $12.6 \pm 2.4$ & & \\
\hline \multirow[t]{2}{*}{ Reserpine } & 18 & $15.7 \pm 13.4$ & $18.5 \pm 7.7$ & $|7.8 \pm 4| .4$ & & \\
\hline & $\mathbf{n}$ & pHIAA & pHIAA & $\Delta \%$ pHIAA & RM ANOVA, time $\times$ group & Post hoc \\
\hline Placebo & 18 & $6.55 \pm 3.3$ & $7.27 \pm 3.7$ & $10.1 \pm 12.1$ & $F_{3,61}=1.5, P=0.217$ & NS \\
\hline Aripiprazole & 18 & $8.26 \pm 4.67$ & $7.53 \pm 3.77$ & $-8.8 \pm 19.3$ & & \\
\hline Haloperidol & 11 & $5.05 \pm 1.5$ & $5.7 I \pm 2.6$ & $12.9 \pm 1.9$ & & \\
\hline \multirow[t]{2}{*}{ Reserpine } & 16 & $7.2 \pm 4.2$ & $5.5 \pm 2.9$ & $-23.6 \pm 3.3$ & & \\
\hline & $\mathbf{n}$ & pMHPG & pMHPG & $\Delta \%$ pMHPG & RM ANOVA, time $\times$ group & Post hoc \\
\hline Placebo & 18 & $5.66 \pm 2.23$ & $5.55 \pm 2.11$ & $-1.5 \pm 2.2$ & $F_{3,59}=5.95, P=0.00 I^{* *}$ & NS \\
\hline Aripiprazole & 16 & $4.98 \pm 2.86$ & $5.58 \pm 2.56$ & $12.1 \pm 10.5$ & & NS \\
\hline Haloperidol & 11 & $6.75 \pm 3.9$ & $6.14 \pm 3.5$ & $-9.1 \pm 8.2$ & & NS \\
\hline Reserpine & 18 & $4.06 \pm 2.14$ & $6.3 \pm 2.9$ & $55.2 \pm 35.5$ & & $P=0.00 I^{* *}$ \\
\hline \multicolumn{7}{|l|}{ Urine } \\
\hline & $\mathbf{N}$ & Day I & Day 8 & $\Delta \%$ uHVA & RM ANOVA, time $\times$ group & Post hoc \\
\hline & & uHVA & uHVA & & & \\
\hline Placebo & 18 & $29.07 \pm 8.5$ & $25.8 \pm 9.7$ & $-11.2 \pm 5.3$ & $F_{3,61}=3.82, P=0.014^{*}$ & NS \\
\hline Aripiprazole & 18 & $24.67 \pm 13.45$ & $28.14 \pm 11.7$ & $14.1 \pm 13$ & & NS \\
\hline Haloperidol & 11 & $30.9 \pm 10.4$ & $32.16 \pm 10$ & $4.1 \pm 3.3$ & & NS \\
\hline \multirow[t]{2}{*}{ Reserpine } & 18 & $24.3 \pm 9.2$ & $37.98 \pm 13.73$ & $56.3 \pm 40.4$ & & $P<0.00 I^{* *}$ \\
\hline & $\mathbf{N}$ & uHIAA & uHIAA & $\Delta \%$ uHIAA & RM ANOVA, time $\times$ group & Post hoc \\
\hline Placebo & 18 & $26.0 \pm 9.7$ & $23.9 \pm 8.9$ & $-8.1 \pm 7.2$ & $F_{3,61}=0.69, P=0.564$ & NS \\
\hline Aripiprazole & 18 & $22.29 \pm 12.6$ & $23.27 \pm 8.5$ & $4.4 \pm 3.1$ & & \\
\hline Haloperidol & 11 & $29.0 \pm 15.8$ & $21.45 \pm 6.9$ & $-26.1 \pm 19.8$ & & \\
\hline \multirow[t]{2}{*}{ Reserpine } & 18 & $24.48 \pm 12.5$ & $20.33 \pm 8.9$ & $16.9 \pm 11.3$ & & \\
\hline & $\mathbf{N}$ & uVMA & uVMA & $\Delta \%$ uVMA & RM ANOVA, time $\times$ group & Post hoc \\
\hline Placebo & 18 & $20.2 \pm 6.8$ & $19.4 \pm 8.1$ & $-4 . I \pm 2.1$ & $F_{3,61}=4.59, P=0.006 * *$ & NS \\
\hline Aripiprazole & 18 & $19.85 \pm 7.7$ & $20.1 \pm 10.3$ & $1.3 \pm 2.5$ & & NS \\
\hline Haloperidol & 11 & $23.4 \pm 8.4$ & $21.1 \pm 6.6$ & $-9.8 \pm 7.6$ & & NS \\
\hline Reserpine & 18 & $16.6 \pm 7.4$ & $25.5 \pm 11.5$ & $53.6 \pm 42.5$ & & $P=0.006 * *$ \\
\hline
\end{tabular}

Notes: $* P<0.05 ; * * P<0.0$ I. Before (day I) and after the 7-day antidopaminergic intervention (day 8 ) in the four groups, outlined as means \pm SD. The mean extent of concentration change after the medication period relative to day I is outlined as $\Delta \%$ ([\{concentration measured on day 8 - concentration measured on day I\}/concentration measured on day I] $\times 100)$.

Abbreviations: HVA, homovanillic acid; RM ANOVA, repeated-measures analysis of variance; HIAA, hydroxyindoleacetic acid; MHPG, 3-methoxy-4-hydroxyphenylglycol; VMA, vanillylmandelic acid. 
time $\times$ group interaction for uHVA $\left(F_{3,61}=3.82, P=0.014\right)$ and uVMA in 24-hour urine $\left(F_{3,61}=4.59, P=0.006\right)$ and for pMHPG $\left(F_{3,59}=5.95, P=0.001\right)$. After Bonferroni correction (adjusted $\alpha=0.008$ ), only the results for pMHPG and uVMA remained statistically significant. There were no significant findings for 5-HIAA or HVA.

For the metabolites with a significant time $\times$ group interaction in the variance analysis, we applied a post hoc analysis, which only in the reserpine group showed a significant change in metabolite levels on day 8 relative to baseline: uHVA increased from $24.3 \pm 9.2$ to $38.0 \pm 13.7 \mathrm{ng} /$ day $(P<0.001)$, uVMA increased from 16.6 \pm 7.4 to $25.5 \pm 11.5 \mathrm{ng} / \mathrm{day}(P=0.006)$, and $\mathrm{pMHPG}$ increased from $4.1 \pm 2.1$ to $6.3 \pm 2.9 \mathrm{ng} / \mathrm{mL}(P=0.001)$ (Figure 1$)$.

\section{Correlations among biogenic amine metabolites, general psychopathology, and different aspects of subjective self- assessment (VAS) after antidopaminergic intervention}

Potential interrelations among catecholamine-metabolite concentrations after subchronic antidopaminergic treatment with observed psychopathological effects (PANSS, HRSD) and different aspects of subjective self-assessment (BDI, VAS) were examined in the entire group of participants receiving an active substance. These data have been reported in detail previously. ${ }^{57}$ Significant correlations were found mainly for pHVA (Table 3). After applying Bonferroni

B
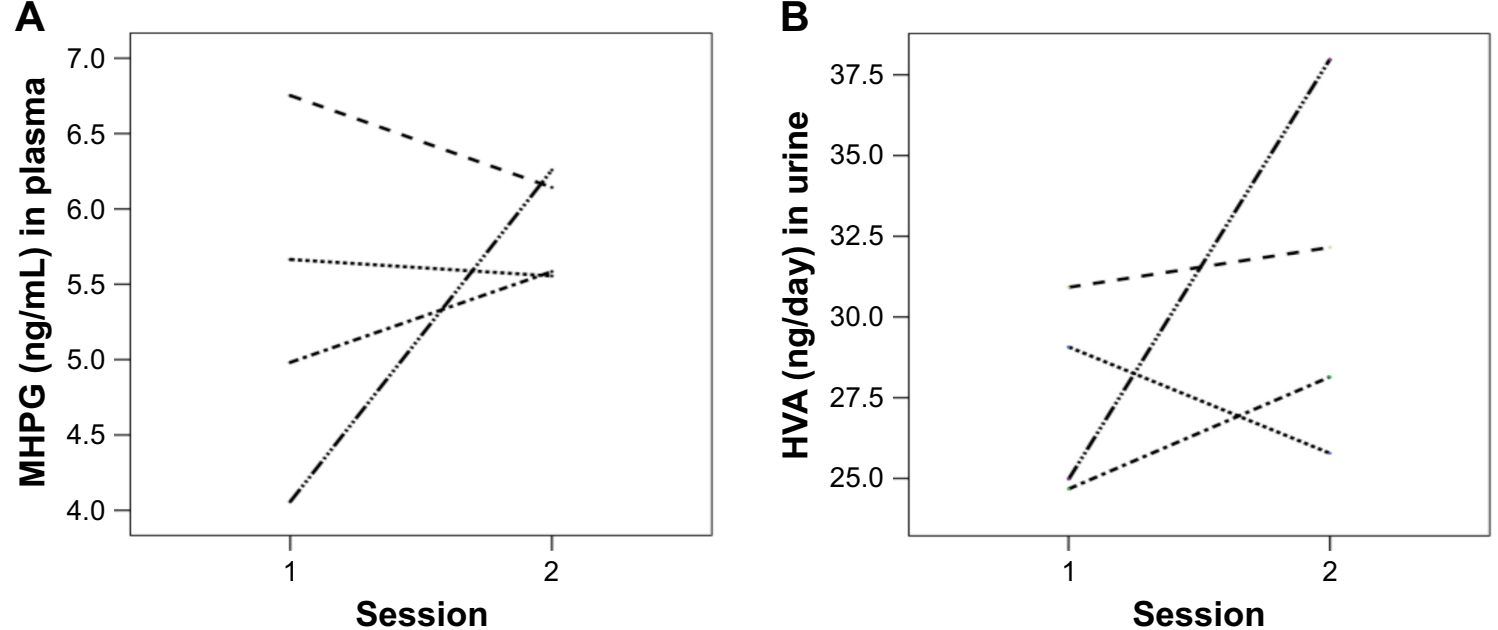

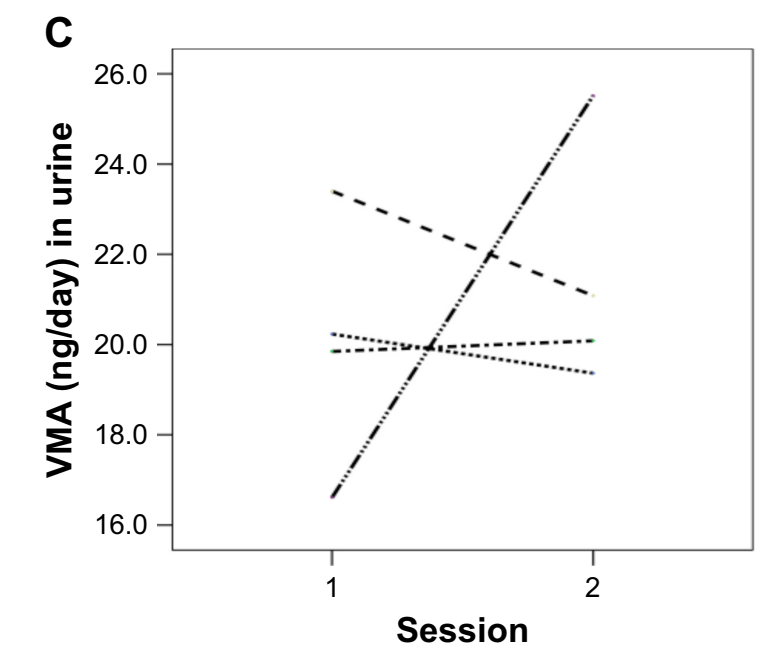

.... Placebo -..- Aripiprazole - - Haloperidol -... Reserpine

Figure I Changes in monoamine metabolite concentrations after the 7-day medication period. Notes: (A) $P=0.00$ I; (B) $P=0.009$; (C) $P=0.006$.

Abbreviations: HVA, homovanillic acid; MHPG, 3-methoxy-4-hydroxyphenylglycol; VMA, vanillylmandelic acid. 
Table 3 Correlations among catecholamine metabolites in plasma and urine, scales for third-party assessment, and subjective assessment of some aspects of the mental condition

\begin{tabular}{|c|c|c|c|c|c|c|}
\hline & $\begin{array}{l}\text { HVA } \\
\text { (plasma) }\end{array}$ & $\begin{array}{l}\text { 5-HIAA } \\
\text { (plasma) }\end{array}$ & $\begin{array}{l}\text { MHPG } \\
\text { (plasma) }\end{array}$ & $\begin{array}{l}\text { HVA } \\
\text { (urine) }\end{array}$ & $\begin{array}{l}\text { 5-HIAA } \\
\text { (plasma) }\end{array}$ & $\begin{array}{l}\text { VMA } \\
\text { (urine) }\end{array}$ \\
\hline \multicolumn{7}{|l|}{ PANNS total } \\
\hline$r$ & $0.51 * *$ & NS & NS & NS & NS & NS \\
\hline$P$ & $<0.001^{* *, \#}$ & & & & & \\
\hline$R^{2}$ & 0.27 & & & & & \\
\hline $\mathrm{BC}_{\mathrm{a}} 95 \% \mathrm{Cl}$ & $0.25-0.70$ & & & & & \\
\hline \multicolumn{7}{|c|}{ PANSS cognitive } \\
\hline$r$ & 0.49 & NS & NS & 0.30 & NS & NS \\
\hline$P$ & $0.00 I^{* * \# \#}$ & & & $0.045^{*}$ & & \\
\hline$R^{2}$ & 0.26 & & & 0.09 & & \\
\hline $\mathrm{BC}_{\mathrm{a}} 95 \% \mathrm{Cl}$ & $0.32-0.66$ & & & -0.01 to 0.15 & & \\
\hline \multicolumn{7}{|c|}{ PANSS depressive } \\
\hline$r$ & 0.37 & NS & NS & NS & NS & NS \\
\hline$P$ & $0.01 *$ & & & & & \\
\hline$R^{2}$ & 0.14 & & & & & \\
\hline $\mathrm{BC}_{\mathrm{a}} 95 \% \mathrm{Cl}$ & $0.02-0.63$ & & & & & \\
\hline \multicolumn{7}{|l|}{ HRSD ${ }^{a}$} \\
\hline$r$ & 0.39 & NS & NS & NS & NS & NS \\
\hline$P$ & $0.007^{*}$ & & & & & \\
\hline$R^{2}$ & 0.15 & & & & & \\
\hline $\mathrm{BC}_{\mathrm{a}} 95 \% \mathrm{Cl}$ & $0.17-0.61$ & & & & & \\
\hline \multicolumn{7}{|l|}{ BDI } \\
\hline$r$ & 0.313 & NS & NS & NS & NS & NS \\
\hline$P$ & 0.03 & & & & & \\
\hline$R^{2}$ & 0.09 & & & & & \\
\hline $\mathrm{BC}_{\mathrm{a}} 95 \% \mathrm{Cl}$ & $0.004-0.57$ & & & & & \\
\hline \multicolumn{7}{|c|}{ VAS ability to concentrate } \\
\hline$r$ & -0.48 & -0.36 & NS & NS & NS & NS \\
\hline$P$ & $0.001 * *, \#$ & $0.015^{*}$ & & & & \\
\hline$R^{2}$ & 0.23 & & & & & \\
\hline $\mathrm{BC}_{\mathrm{a}} 95 \% \mathrm{Cl}$ & -0.65 to -0.31 & -0.53 to -0.20 & & & & \\
\hline \multicolumn{7}{|c|}{ VAS general well-being } \\
\hline$r$ & -0.44 & -0.46 & NS & NS & NS & NS \\
\hline$P$ & $0.002 * * * \#$ & $0.002 * *, \#$ & & & & \\
\hline$R^{2}$ & 0.19 & 0.21 & & & & \\
\hline $\mathrm{BC}_{\mathrm{a}} 95 \% \mathrm{Cl}$ & -0.64 to 0.22 & -0.62 to -0.3 & & & & \\
\hline \multicolumn{7}{|l|}{ VAS fatigue } \\
\hline$r$ & 0.37 & NS & NS & NS & NS & NS \\
\hline$P$ & $0.011 *$ & & & & & \\
\hline$R^{2}$ & 0.14 & & & & & \\
\hline $\mathrm{BC}_{\mathrm{a}} 95 \% \mathrm{Cl}$ & $0.14-0.61$ & & & & & \\
\hline \multicolumn{7}{|l|}{ VAS motivation } \\
\hline$r$ & NS & NS & NS & NS & NS & NS \\
\hline \multicolumn{7}{|l|}{$P$} \\
\hline \multicolumn{7}{|l|}{$R^{2}$} \\
\hline \multicolumn{7}{|l|}{$\mathrm{BC}_{\mathrm{a}} 95 \% \mathrm{Cl}$} \\
\hline \multicolumn{7}{|l|}{ VAS drive } \\
\hline$r$ & -0.34 & NS & NS & NS & NS & NS \\
\hline$P$ & $0.021 *$ & & & & & \\
\hline$R^{2}$ & 0.12 & & & & & \\
\hline $\mathrm{BC}_{\mathrm{a}} 95 \% \mathrm{Cl}$ & -0.62 to -0.05 & & & & & \\
\hline
\end{tabular}

Notes: $* P<0.05 ; * * P<0.01$; **.\#correlations remaining significant after Bonferroni correction (corrected significance level for ten scores and six metabolites $P=0.003$ ). Scales for third-party assessment (PANSS and HRSD) and assessment of mental condition (VAS and BDI) in the verum group measured on day 8 (24 hours after cessation of antidopaminergic intervention). PANSS subscales defined by the Lindenmayer et al model ${ }^{52}$ were analyzed separately.

Abbreviations: HVA, homovanillic acid; RM ANOVA, repeated-measures analysis of variance; HIAA, hydroxyindoleacetic acid; MHPG, 3-methoxy-4-hydroxyphenylglycol; VMA, vanillylmandelic acid; PANSS, Positive and Negative Syndrome Scale; HRSD, Hamilton Rating Scale for Depression; VAS, visual analogue scale; BDI, Beck Depression Inventory; $\mathrm{BC}_{\mathrm{a}}$, bias corrected and accelerated; NS, not significant. 
correction (adjusted significance level 0.003), pHVA remained significantly positively correlated with PANSS total score and PANSS cognitive component. Further, pHVA correlated significantly negatively with subjective assessment of ability to concentrate and subjective assessment of general well-being. The correlation with the HRSD score fell just short of significance. pHIAA showed a significant negative correlation with subjective assessments of ability to concentrate and with general well-being. In sum, higher day 8 pHVA levels were associated with higher PANSS scores (PANSS total, PANSS cognitive), higher HRSD scores, and lower self-assessment of well-being and ability to concentrate. The last two items also correlated negatively with pHIAA.

\section{Differences in psychopathology and subjective assessment with respect to changes in plasma prolactin}

In our initial analysis of these data, we noted a significant increase in prolactin after treatment with haloperidol and reserpine but not aripiprazole. ${ }^{54}$ In order to examine the association between this increase and the subjective and objective measures of psychopathology, the scores obtained were compared between two subgroups of active drug recipients stratified for high prolactin increase $(>50 \%$ from baseline, mean \pm SD $236 \% \pm 189 \%, n=35)$ and little or no prolactin increase $(<50 \%$ from baseline, mean $\pm \mathrm{SD}, 15.5 \% \pm 32.5 \%$, $n=19$ ) (Table 4). A one-way multivariate analysis of covariance (MANCOVA) was carried out using the subgroup affiliation as independent variable to examine the relationship

Table 4 Prolactin changes vs scales for third-party and subjective assessment

\begin{tabular}{llll}
\hline & $\begin{array}{l}\text { Prolactin } \\
\text { increase } \\
<\mathbf{5 0} \%\end{array}$ & $\begin{array}{l}\text { Prolactin } \\
\text { increase } \\
(\mathbf{n}=\mathbf{1 9})\end{array}$ & $\begin{array}{l}\text { One-way } \\
\text { ANCOVA }\end{array}$ \\
& $\mathbf{( n = 3 5 )}$ & \\
\hline PANSS total & $41.2 \pm 9.2$ & $53.5 \pm 12.3$ & $F_{1,51}=14.45, P<0.001$ \\
PANSS cognitive & $7.4 \pm 2.9$ & $9.3 \pm 2.7$ & $F_{1,51}=5.6, P=0.022$ \\
PANSS depressive & $5.4 \pm 0.8$ & $8.5 \pm 3.7$ & $F_{1,51}=13.1, P=0.001$ \\
HRSD & $3.6 \pm 3.9$ & $8.3 \pm 6.9$ & $F_{1,51}=7, P=0.01$ \\
BDI & $1.3 \pm 1.9$ & $4.3 \pm 4.9$ & $F_{1,51}=7.4, P=0.009$ \\
VAS ability to concentrate & $64.1 \pm 25.9$ & $42.7 \pm 27.7$ & $F_{1,51}=7.5, P=0.008$ \\
VAS general well-being & $64.8 \pm 26.8$ & $48.2 \pm 25.9$ & $F_{1,51}=4.9, P=0.03$ \\
VAS fatigue & $47.1 \pm 28.6$ & $56.7 \pm 24.6$ & $F_{1,51}=1.6, P=0.217$ \\
VAS motivation & $64.4 \pm 23.4$ & $46.9 \pm 25.8$ & $F_{1,51}=5.1, P=0.028$ \\
VAS drive & $66.7 \pm 20.7$ & $44.3 \pm 26.2$ & $F_{1,51}=10.1, P=0.003$ \\
\hline ADSrevian
\end{tabular}

Abbreviations: ANCOVA, analysis of covariance; PANSS, Positive and Negative Syndrome Scale; HRSD, Hamilton Rating Scale for Depression; BDI, Beck Depression Inventory; VAS, visual analogue scale. between prolactin increase and PANSS, HRSD, BDI, and VAS for general well-being, subjective ability to concentrate, fatigue, motivation, and drive as dependent variables and with sex as a covariate. The MANCOVA revealed a significant effect of subgroup affiliation (Pillai's trace $\left.V=0.357, F_{10.42}=2.34 ; P=0.027\right)$. After Bonferroni correction (adjusted significance level 0.005), separate univariate ANOVAs remained significant for the outcome variables PANSS $\left(F_{1,51}=14.45, P<0.001\right)$, PANSS depressive compo$\operatorname{nent}\left(F_{1,51}=13.1, P=0.001\right)$. VAS drive $\left(F_{1,51}=10.1, P=0.003\right)$. BDI $\left(F_{1,51}=7.4, P=0.009\right)$ and VAS ability to concentrate $\left(F_{1,51}=7.5, P=0.008\right)$ were nearly significant (Figure 2$)$.

In one additional exploratory analysis, we examined whether change in prolactin level was indicative of medication tolerability (Table 5). Within the haloperidol group, dropouts (subjects who terminated participation ahead of schedule due to intolerable side effects) showed a significantly higher increase in prolactin levels than subjects who completed the entire study protocol $(361 \pm 99$ vs $278 \pm 155$, Mann-Whitney $U$ test $P=0.015$ ).

\section{Discussion}

In this single-blind, randomized, placebo-controlled study, 72 healthy participants received either an antidopaminergic substance or placebo for 7 days. We tested for interdependence between psychopathological and physiological effects of subchronic antidopaminergic treatments at doses typical of those employed in off-label applications (but less than in treatment of psychosis). Only the challenge with reserpine significantly altered catecholamine metabolites, ie, increased pMHPG and 24-hour uHVA and uVMA. This is in line with previous findings in animals treated with reserpine alkaloids, ${ }^{59}$ and is consistent with peripheral and central depletion of catecholamines, despite the low reserpine dose. Increased metabolism follows degranulation of synaptic vesicles, which exposes intracellular dopamine and norepinephrine pools to rapid metabolism by monoamine oxidase. Consecutively, partial depletion of brain dopamine resulted in impaired subjective state, psychopathological conspicuities, and diminished cognitive performance.

The lack of effects of subchronic haloperidol or aripiprazole treatment on plasma- or urine-metabolite concentrations was somewhat unexpected, considering the established acute effects of these compounds on dopamine turnover in the brain, manifesting in increased metabolite levels in brain, cerebrospinal fluid, and urine, ${ }^{60-62}$ although some contrary results have also been reported. ${ }^{63}$ Interestingly, several studies have shown that the clinical response to 


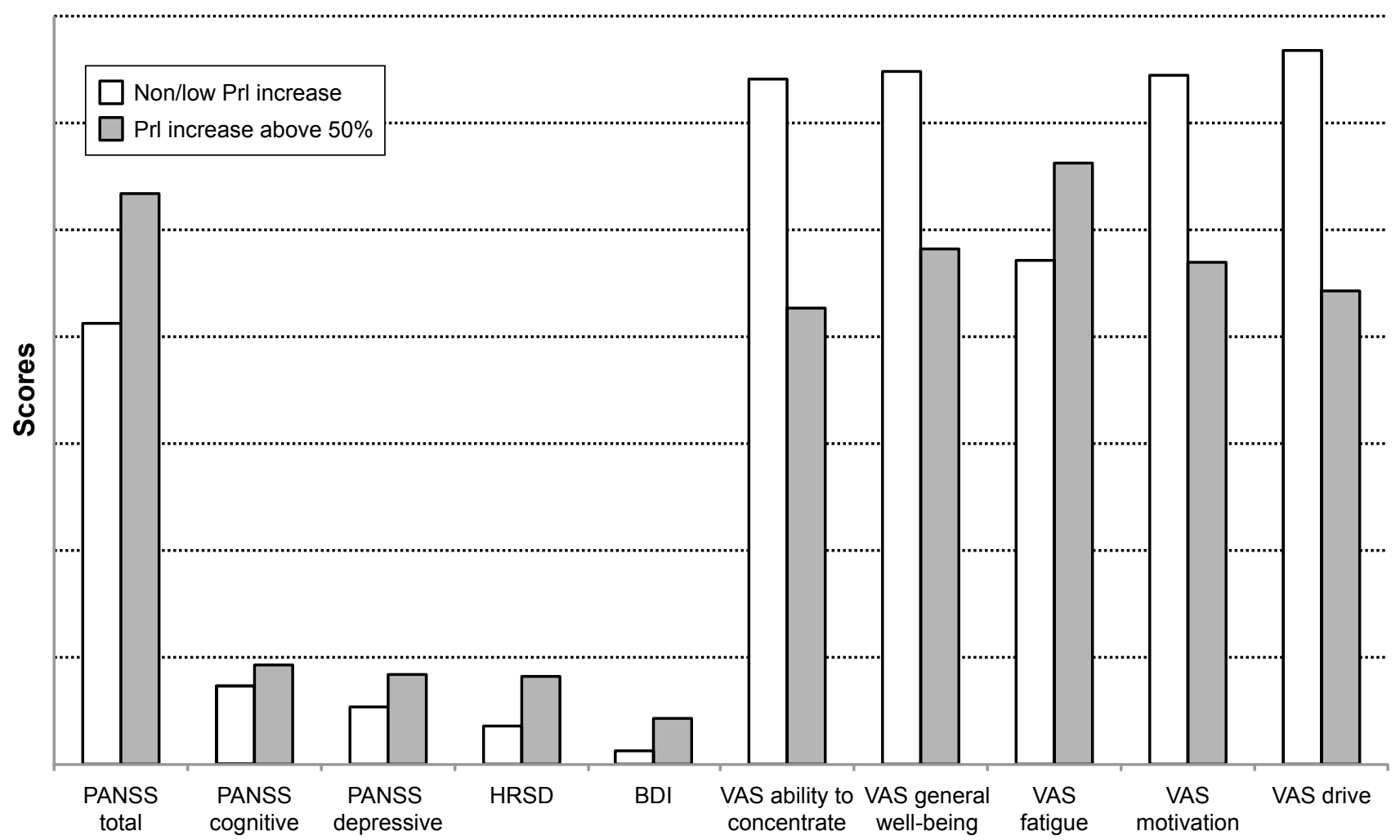

Figure 2 Prolactin (Prl) changes versus scales for third-party and subjective assessment.

Abbreviations: PANSS, Positive and Negative Syndrome Scale; HRSD, Hamilton Rating Scale for Depression; BDI, Beck Depression Inventory; VAS, visual analogue scale.

antipsychotic medication (ie, a decrease in psychosis-rating scores) in schizophrenia parallels a decrease in pHVA over time. ${ }^{64-71}$ This phenomenon has been linked to the concept of delayed depolarization block, in which therapeutic response follows a partial inactivation of brain dopamine neurons. ${ }^{72}$ Conversely, some studies have revealed an initial increase in pHVA during the first week of antipsychotic drug treatment paralleling an acute decrease in psychotic symptoms, ${ }^{23,66,73}$ which seems consistent with an acute stimulation of dopamine synthesis due to autoreceptor blockade. Further, decreasing pHVA levels have also been reported as an attribute of responder stats to treatment with antipsychotics. $^{74-77}$

Table 5 Prolactin concentrations ( $\mathrm{mU} / \mathrm{L})$ before and after 7-day medication period

\begin{tabular}{llll}
\hline Treatment group & Baseline & $\begin{array}{l}\text { After medication } \\
\text { period }\end{array}$ & Difference \\
\hline Placebo & $211.6 \pm 113.4$ & $196.1 \pm 85.6$ & $-15.4 \pm 66$ \\
Aripiprazole & $160.9 \pm 65$ & $189.6 \pm 209.6$ & $28.7 \pm 219.1$ \\
Haloperidol & $177.2 \pm 74.6$ & $350.7 \pm 202.6$ & $173.5 \pm 177.1$ \\
$\quad$ Completers $(n=11)$ & $204.5 \pm 87.3$ & $277.7 \pm 155.5$ & $73.3 \pm 109.5$ \\
$\quad$ Dropouts $(n=7)$ & $139.1 \pm 28.6$ & $360.6 \pm 98.7$ & $221.43 \pm 87.7$ \\
Reserpine & $149.6 \pm 80.2$ & $540.3 \pm 280.8$ & $390.7 \pm 263.7$ \\
\hline
\end{tabular}

Opposite to these findings observed in patients with schizophrenia, in our study the 7-day treatment with haloperidol and aripiprazole did not induce a detectable change in pHVA concentration in healthy volunteers. Keeping in mind that less than a third of pHVA is likely derived from the brain, one possible explanation may be that the effects of the low doses of haloperidol and aripiprazole on plasma-metabolite levels may have been too low to be registered.

Further, seven of 20 subjects in our haloperidol group withdrew from the study due to adverse experiences; this reduced the statistical power of our haloperidol arm, but may also have introduced bias, in that (by excluding these seven from consideration) we inadvertently selected for individuals with lesser sensitivity to haloperidol. We have previously seen that haloperidol challenge can have a range of effects on human cognition in healthy volunteers, with three of nine subjects experiencing improvement in some cognitive domains after treatment for 3 days with haloperidol. ${ }^{78}$ Therefore, haloperidol at the present dose regimen may have unmasked a subgroup of seven healthy individuals with higher-than-average responsiveness. However, we detected no distinctive features in this small subgroup concerning their demographic characteristics or monoamine metabolite levels at baseline. Interestingly, they did show significantly 
greater acute stimulation of prolactin release than subjects who tolerated the haloperidol intake for the whole scheduled period of 7 days.

Present neutral findings with aripiprazole are particularly interesting with regard to the distinct mechanism of action of aripiprazole via partial dopamine-receptor agonism and functional selectivity. ${ }^{79,80}$ In cerebral microdialysis studies, acute aripiprazole strongly increased interstitial dopamine metabolites, while reducing 5-HIAA levels in rat prefrontal cortex and striatum. In contrast, chronic administration of aripiprazole produced "stabilization", with less pronounced effects in interstitial metabolites of dopamine and serotonin, consistent with present findings in healthy humans with subchronic treatment. Furthermore, aripiprazole may have net agonist effects at presynaptic $\mathrm{D}_{2 / 3}$ autoreceptors, with net antagonism at postsynaptic receptors, ${ }^{81}$ which would likely cause a dissociation between behavioral/cognitive effects and altered dopamine turnover. ${ }^{82,83}$ This proposition is in line with the relatively good tolerability and fewer side effects observed in the group treated with aripiprazole.

The subchronic antidopaminergic interventions in our study provoked a range of subjective and objective psychopathological impairments, which we have reported in detail previously. ${ }^{57,58}$ Our regression analyses showed these impairments were in some manner "synchronized" with posttreatment pHVA levels, consistent with a fundamental relationship with dopaminergic turnover in brain, despite the imperfect representation between pHVA and central dopamine. Friedhoff ${ }^{84}$ suggested that there might be a dopamine-dependent restorative system responsible for the maintenance of mental stability, whereby dopaminergic activity is normally regulated in the face of biological or psychological stressors. We suppose that present antidopaminergic interventions may have challenged this restorative system, unmasking an inherent association between pHVA levels with objective and subjective psychopathological impairments in healthy individuals.

Associations between pHVA and several mental domains have already been reported in different psychiatric diseases. A large body of clinical research has linked altered pHVA levels with psychotic states, ${ }^{28}$ symptom severity, ${ }^{85,86}$ negative symptoms, and anhedonia, ${ }^{87,88}$ as well as the occurrence of relapse of psychotic symptoms ${ }^{89}$ in schizophrenia. Furthermore, correlations between pHVA concentrations and psychotic symptoms have also been observed in delirium ${ }^{90}$ and Alzheimer's disease. ${ }^{91}$

In our study, higher pHVA levels upon medication were associated with lower general well-being and self-assessed ability to concentrate in healthy volunteers treated with antidopaminergic compounds. These findings supplement observations about negative subjective experiences during treatment with antipsychotics, ${ }^{92-95}$ which are associated with higher $\mathrm{D}_{2}$-receptor occupancy ${ }^{96-99}$ in schizophrenia patients. Further, in our study pHVA also correlated with some objective and subjective items related to cognition (PANSS cognitive and VAS ability to concentrate). In our previous report, we showed that the antidopaminergic interventions resulted in pronounced impairments in the domains of information-processing speed, attention, and learning. ${ }^{58}$ Others have reported significant correlations between $\mathrm{pHVA}$ and stress experienced during performance of arithmetic tasks. ${ }^{30}$ Overall, the present association between impaired well-being and generally assessed cognitive impairments after antidopaminergic intervention with increased pHVA levels presents a mechanism for iatrogenic effects of off-label use of this class of compounds.

We now extend our earlier presentation of antidopaminergic effects on prolactin ${ }^{54}$ secretion to establish this as a surrogate marker for central effects. In the subgroup of healthy volunteers with $>50 \%$ increase in prolactin relative to baseline, we saw significantly greater general psychopathological impairments (PANSS score) and depressive symptoms (PANSS depressive), with a statistical trend toward lower self-assessment of well-being and concentration ability. This result concurs with a recent study performed in healthy volunteers, where higher baseline prolactin levels had a strong association with poorer cognition, well-being, and mood in healthy men. ${ }^{100}$ A similar association has been reported in late-pregnancy and postpartum women, ${ }^{101}$ and in relation to depression in women. ${ }^{102}$ An association between increased prolactin levels and impaired processing speed has been reported in early-psychosis patients, ${ }^{103}$ although declining prolactin levels after switching to aripiprazole were not associated with cognitive improvement in chronic patients. ${ }^{104}$

A supplementary analysis revealed an association between the tolerability of haloperidol and the extent of prolactin increase. Those subjects experiencing side effects leading to dropout showed a significantly greater initial prolactin increase than those who tolerated haloperidol for 7 days. The association between prolactin increase (and subsequent hyperprolactinemia) and treatment with antipsychotic medication is a phenomenon replicated in numerous investigations since the 1970 s. ${ }^{105}$ Treatments with risperidone, amisulpride, sulpiride, and first-generation antipsychotics are known to cause the highest rates of 
hyperprolactinemia. ${ }^{106}$ Further, multiple signs and symptoms have been described to emerge as a consequence of such pharmacologically induced hyperprolactinemia, ie, gynecomastia, galactorrhea, sexual dysfunction, infertility, oligomenorrhea, amenorrhoea, ${ }^{107}$ sexual dysfunction, decreased bone-mineral density (which may lead to increased risk of osteoporosis), and even increased risk of breast cancer and possibly prostate cancer. ${ }^{108}$ The present results thus indicate that iatrogenic hyperprolactinemia could serve as a predictor of objective psychopathological and cognitive impairments and general tolerability in the off-label use of antidopaminergic compounds.

\section{Limitations and conclusion}

As noted, only a third of pHVA and pMHPG originates from the human brain. ${ }^{109,110}$ Nevertheless, the use of pHVA as an index of central dopaminergic activity is supported by several studies in humans where treatment with a peripherally acting monoamine oxidase inhibitor did not ablate the relationship between cerebrospinal fluid HVA and residual pHVA. $^{76,21,111}$ Although our use of the PANSS to assess changes in mental condition in healthy controls may seem controversial, it is justified by the present search for provoked psychopathological abnormalities after antidopaminergic interventions. Indeed, the PANSS proved sensitive to revealing such changes following rather low doses of the medications. Finally, the chosen antidopaminergic substances do not represent the commonly and most frequently off-label used antidopaminergic drugs. Indeed, our decision was primarily guided by the aim to examine the effects of the largely different antidopaminergic mechanisms of action represented by the selected substances. We concede the need in future studies to consider the use of quetiapine or risperidone, which are more commonly prescribed for off-label indications than the present medications.

Despite these caveats, we demonstrated that pharmacological perturbation of central dopaminergic transmission through antidopaminergic interventions in healthy volunteers provoked several objective and subjective mental impairments, which proved to correlate with increases in plasma levels of HVA and prolactin. Furthermore, our results suggest that early hyperprolactinemia could be predictive of tolerability of longer-term treatment, and thus spare patients risk from iatrogenic disease. Overall, the present results draw attention to the potent effects on dopamine-mediated processes evoked by antidopaminergic compounds, even when administered at the low doses typical of off-label indications.

\section{Acknowledgments}

This study was supported by the START Program of the Medical Faculty of RWTH Aachen University and the International Research and Training Group (IRTG1328) of the German Research Foundation (DFG). Aripiprazole was kindly provided by Bristol-Myers Squibb $\mathrm{GmbH}$ and $\mathrm{Co}$ $\mathrm{KGaA}$, Munich, Germany. The authors note assistance from Inglewood Biomedical Editing in preparing the manuscript. They further thank Andre Kirner and Ger Janssen for helpful suggestions.

\section{Disclosure}

TV has received grant support from Bristol-Myers Squibb. IV has served on the speakers' bureaux of Bristol-Myers Squibb (New York, NY), Eli Lilly (Indianapolis, IN), and GlaxoSmithKline (London, UK). GG has served as a consultant for Allergan, Boehringer Ingelheim, Eli Lilly, JanssenCilag, Lundbeck, Ono Pharmaceuticals, Otsuka, Recordati, Roche, Servier, and Takeda, and served on the speakers' bureaux of Eli Lilly, Janssen Cilag, Lundbeck, Neuraxpharm, Otsuka, Roche, Servier, and Trommsdorff. He has received grant support from Boehringer Ingelheim and Roche, and is cofounder of Pharma Image and Brainfoods $\mathrm{GmbH}$. The other authors report no conflicts of interest in this work.

\section{References}

1. Andréoli L, Gaudoneix M, Beauverie P, de Beaurepaire R. [Off-label prescriptions in public psychiatric hospital practice]. Therapie. 2013; 68(6):347-359. French.

2. Assion HJ, Jungck C. Off-label prescribing in a German psychiatric hospital. Pharmacopsychiatry. 2007;40(1):30-36.

3. Haw C, Stubbs J. Off-label psychotropic prescribing for young persons in medium security. J Psychopharmacol. 2010;24(10):1491-1498.

4. Mark TL. For what diagnoses are psychotropic medications being prescribed? A nationally representative survey of physicians. CNS Drugs. 2010;24(4):319-326.

5. Thompson W, Quay TA, Rojas-Fernandez C, Farrell B, Bjerre LM. Atypical antipsychotics for insomnia: a systematic review. Sleep Med. 2016;22:13-17.

6. Walitt B, Klose P, Uçeyler N, Phillips T, Häuser W. Antipsychotics for fibromyalgia in adults. Cochrane Database Syst Rev. 2016;(6): CD011804.

7. Nieoullon A. Dopamine and the regulation of cognition and attention. Prog Neurobiol. 2002;67(1):53-83.

8. Hori H, Noguchi H, Hashimoto R, et al. Antipsychotic medication and cognitive function in schizophrenia. Schizophr Res. 2006;86(1-3): $138-146$.

9. Knowles EE, David AS, Reichenberg A. Processing speed deficits in schizophrenia: reexamining the evidence. Am J Psychiatry. 2010;167(7): 828-835.

10. Torniainen M, Suvisaari J, Partonen T, et al. Cognitive impairments in schizophrenia and schizoaffective disorder: relationship with clinical characteristics. J Nerv Ment Dis. 2012;200(4):316-322.

11. Husa AP, Rannikko I, Moilanen J, et al. Lifetime use of antipsychotic medication and its relation to change of verbal learning and memory in midlife schizophrenia: an observational 9-year follow-up study Schizophr Res. 2014;158(1-3):134-141. 
12. Husa AP, Moilanen J, Murray GK, et al. Lifetime antipsychotic medication and cognitive performance in schizophrenia at age 43 years in a general population birth cohort. Psychiatry Res. 2017;247:130-138.

13. Mishara AL, Goldberg TE. A meta-analysis and critical review of the effects of conventional neuroleptic treatment on cognition in schizophrenia: opening a closed book. Biol Psychiatry. 2004;55(10):1013-1022.

14. Harvey PD, Keefe RS. Studies of cognitive change in patients with schizophrenia following novel antipsychotic treatment. Am J Psychiatry. 2001;158(2):176-184.

15. Zhang JP, Gallego JA, Robinson DG, Malhotra AK, Kane JM, Correll CU. Efficacy and safety of individual second-generation vs. first-generation antipsychotics in first-episode psychosis: a systematic review and meta-analysis. Int J Neuropsychopharmacol. 2013;16(6):1205-1218.

16. Cumming P. Imaging Dopamine. Cambridge: Cambridge University Press; 2009.

17. Amin F, Davidson M, Davis KL. Homovanillic acid measurement in clinical research: a review of methodology. Schizophr Bull. 1992;18(1): 123-148.

18. Bacopoulos NG, Hattox SE, Roth RH. 3,4-Dihydroxyphenylacetic acid and homovanillic acid in rat plasma: possible indicators of central dopaminergic activity. Eur J Pharmacol. 1979;56(3):225-236.

19. Kendler KS, Hsieh JY, Davis KL. Studies of plasma homovanillic acid as an index of brain dopamine function. Psychopharmacol Bull. 1982;18(4):152-155.

20. Lambert GW, Eisenhofer G, Jennings GL, Esler MD. Regional homovanillic acid production in humans. Life Sci. 1993;53(1):63-75.

21. Maas JW, Contreras SA, Miller AL, et al. Studies of catecholamine metabolism in schizophrenia/psychosis - I. Neuropsychopharmacology. 1993;8(2):97-109

22. Arrue A, Davila R, Zumarraga M, et al. GABA and homovanillic acid in the plasma of schizophrenic and bipolar I patients. Neurochem Res. 2010;35(2):247-253.

23. Duncan E, Wolkin A, Angrist B, et al. Plasma homovanillic acid in neuroleptic responsive and nonresponsive schizophrenics. Biol Psychiatry. 1993;34(8):523-528.

24. Javaid JI, Sharma RP, Janicak PG, Davis JM. Plasma HVA in psychiatric patients: longitudinal studies. Psychopharmacol Bull. 1990;26(3): 361-365.

25. Kakihara S, Yoshimura R, Shinkai K, et al. Prediction of response to risperidone treatment with respect to plasma concentrations of risperidone, catecholamine metabolites, and polymorphism of cytochrome P450 2D6. Int Clin Psychopharmacol. 2005;20(2):71-78.

26. Kelley ME, Yao JK, van Kammen DP. Plasma catecholamine metabolites as markers for psychosis and antipsychotic response in schizophrenia. Neuropsychopharmacology. 1999;20(6):603-611.

27. Koreen AR, Lieberman J, Alvir J, et al. Plasma homovanillic acid levels in first-episode schizophrenia: psychopathology and treatment response. Arch Gen Psychiatry. 1994;51(2):132-138.

28. Mazure CM, Nelson JC, Jatlow PI, Bowers MB. Plasma free homovanillic acid (HVA) as a predictor of clinical response in acute psychosis. Biol Psychiatry. 1991;30(5):475-482.

29. Petrie EC, Faustman WO, Moses JA, Lombrozo L, Csernansky JG. Correlates of rapid neuroleptic response in male patients with schizophrenia. Psychiatry Res. 1990;33(2):171-177.

30. Sumiyoshi T, Kurachi M, Kurokawa K, et al. Plasma homovanillic acid in the prodromal phase of schizophrenia. Biol Psychiatry. 2000;47(5): $428-433$.

31. Soda E, Miura I, Hoshino H, et al. Impacts of age on plasma monoamine metabolite concentrations in a large cohort of healthy individuals. Psychiatry Res. 2014;220(1-2):639-645.

32. Kumakura Y, Vernaleken I, Buchholz HG, et al. Age-dependent decline of steady state dopamine storage capacity of human brain: an FDOPA PET study. Neurobiol Aging. 2017;31(3):447-463.

33. Lee R, Coccaro EF. Plasma homovanillic acid correlates inversely with history of childhood trauma in personality disordered and healthy control adults. J Neural Transm. 2010;117(11):1327-1334.
34. Roy A. Self-rated childhood emotional neglect and CSF monoamine indices in abstinent cocaine-abusing adults: possible implications for suicidal behavior. Psychiatry Res. 2002;112(1):69-75.

35. Sumiyoshi T, Yotsutsuji T, Kurachi M, Itoh H, Kurokawa K, Saitoh O. Effect of mental stress on plasma homovanillic acid in healthy human subjects. Neuropsychopharmacology. 1998;19(1):70-73.

36. Fitzgerald P, Dinan TG. Prolactin and dopamine: what is the connection? A review article. J Psychopharmacol. 2008;22(2 Suppl):12-19.

37. Ben-Jonathan N, Hnasko R. Dopamine as a prolactin (PRL) inhibitor. Endocr Rev. 2001;22(6):724-763.

38. Molitch ME. Medication-induced hyperprolactinemia. Mayo Clin Proc. 2005;80(8):1050-1057.

39. Meltzer HY, Fang VS. The effect of neuroleptics on serum prolactin in schizophrenic patients. Arch Gen Psychiatry. 1976;33(3):279-286.

40. Gründer G, Wetzel H, Schlösser R, et al. Neuroendocrine response to antipsychotics: effects of drug type and gender. Biol Psychiatry. 1999; 45(1):89-97.

41. Deutschländer A, la Fougère $C$, Boetzel K, et al. Occupancy of pramipexole (Sifrol) at cerebral dopamine D2/3 receptors in Parkinson's disease patients. Neuroimage Clin. 2016;12:41-46.

42. Frank MJ, O’Reilly RC. A mechanistic account of striatal dopamine function in human cognition: psychopharmacological studies with cabergoline and haloperidol. Behav Neurosci. 2006;120(3):497-517.

43. First MB, Spitzer RL, Gibbon M, Williams JB. Structured Clinical Interview for DSM-IV-TR Axis I Disorders, Research Version. Nonpatient ed. New York: Biometrics Research; 2002.

44. Davies MA, Sheffler DJ, Roth BL. Aripiprazole: a novel atypical antipsychotic drug with a uniquely robust pharmacology. CNS Drug Rev. 2004;10(4):317-336.

45. Roth BL, Sheffler DJ, Kroeze WK. Magic shotguns versus magic bullets: selectively non-selective drugs for mood disorders and schizophrenia. Nat Rev Drug Discov. 2004;3(4):353-359.

46. Berlant JL. Neuroleptics and reserpine in refractory psychoses. J Clin Psychopharmacol. 1986;6(3):180-184.

47. Henry JP, Botton D, Sagne C, et al. Biochemistry and molecular biology of the vesicular monoamine transporter from chromaffin granules. J Exp Biol. 1994;196:251-262.

48. Kannari K, Tanaka H, Maeda T, Tomiyama M, Suda T, Matsunaga M. Reserpine pretreatment prevents increases in extracellular striatal dopamine following L-dopa administration in rats with nigrostriatal denervation. J Neurochem. 2000;74(1):263-269.

49. Beck AT, Ward CH, Mendelson M, Mock J, Erbaugh J. An inventory for measuring depression. Arch Gen Psychiatry. 1961;4:561-571.

50. Hamilton M. A rating scale for depression. J Neurol Neurosurg Psychiatry. 1960;23:56-62.

51. Kay SR, Fiszbein A, Opler LA. The positive and negative syndrome scale (PANSS) for schizophrenia. Schizophr Bull. 1987;13(2):261-276.

52. Lindenmayer JP, Bernstein-Hyman R, Grochowski S, Bark N. Psychopathology of schizophrenia: initial validation of a 5-factor model. Psychopathology. 1995;28(1):22-31.

53. Marsh-Richard DM, Hatzis ES, Mathias CW, Venditti N, Dougherty DM. Adaptive visual analog scales (AVAS): a modifiable software program for the creation, administration, and scoring of visual analog scales. Behav Res Methods. 2009;41(1):99-106.

54. Veselinović T, Schorn H, Vernaleken IB, Schiffl K, Klomp M, Gründer G. Impact of different antidopaminergic mechanisms on the dopaminergic control of prolactin secretion. J Clin Psychopharmacol. 2011; 31(2):214-220

55. Minegishi A, Ishizaki T. Determination of free 3-methoxy-4-hydroxyphenylglycol with several other monoamine metabolites in plasma by high-performance liquid chromatography with amperometric detection. J Chromatogr. 1984;311(1):51-57.

56. Davidson DF. Simultaneous assay for urinary 4-hydroxy-3-methoxymandelic acid, 5-hydroxyindoleacetic acid and homovanillic acid by isocratic HPLC with electrochemical detection. Ann Clin Biochem. 1989;26(Pt 2):137-143. 
57. Veselinović T, Schorn H, Vernaleken I, et al. Effects of antipsychotic treatment on psychopathology and motor symptoms: a placebocontrolled study in healthy volunteers. Psychopharmacology (Berl). 2011;218(4):733-748.

58. Veselinović T, Schorn H, Vernaleken IB, et al. Effects of antipsychotic treatment on cognition in healthy subjects. J Psychopharmacol. 2013; 27(4):374-385.

59. Sreemantula S, Boini KM, Nammi S. Reserpine methonitrate, a novel quaternary analogue of reserpine augments urinary excretion of VMA and 5-HIAA without affecting HVA in rats. BMC Pharmacol. 2004:4:30

60. Carlsson A, Lindqvist M. Effect of chlorpromazine or haloperidol on formation of 3-methoxytyramine and normetanephrine in mouse brain. Acta Pharmacol Toxicol (Copenh). 1963;20:140-144.

61. Karoum F, Chrapusta SJ, Egan MF. 3-Methoxytyramine is the major metabolite of released dopamine in the rat frontal cortex: reassessment of the effects of antipsychotics on the dynamics of dopamine release and metabolism in the frontal cortex, nucleus accumbens, and striatum by a simple two pool model. J Neurochem. 1994;63(3):972-979.

62. O'Keeffe R, Sharman DF, Vogt M. Effect of drugs used in psychoses on cerebral dopamine metabolism. Br J Pharmacol. 1970;38(2): 287-304.

63. Magliozzi JR, Doran AR, Gietzen DW, Olson AM, Maclin EL, Tuason VB. Effects of single dose haloperidol administration on plasma homovanillic acid levels in normal subjects. Psychiatry Res. 1993;47(2):141-149.

64. Davidson M, Davis KL. A comparison of plasma homovanillic acid concentrations in schizophrenic patients and normal controls. Arch Gen Psychiatry. 1988;45(6):561-563.

65. Hori H, Yoshimura R, Yamada Y, et al. Effects of olanzapine on plasma levels of catecholamine metabolites, cytokines, and brain-derived neurotrophic factor in schizophrenic patients. Int Clin Psychopharmacol. 2007;22(1):21-27.

66. Davila R, Gonzalez MA, Zumarraga M, et al. Plasma prolactin and plasma homovanillic acid: predictors of clinical response in schizophrenia. Biol Psychiatry. 1995;38(4):267-269.

67. Pickar D, Labarca R, Linnoila M, et al. Neuroleptic-induced decrease in plasma homovanillic acid and antipsychotic activity in schizophrenic patients. Science. 1984;225(4665):954-957.

68. Pickar D, Labarca R, Doran AR, et al. Longitudinal measurement of plasma homovanillic acid levels in schizophrenic patients: correlation with psychosis and response to neuroleptic treatment. Arch Gen Psychiatry. 1986;43(7):669-676.

69. Sharma R, Javaid JI, Janicak P, Faull K, Comaty J, Davis JM. Plasma and CSF HVA before and after pharmacological treatment. Psychiatry Res. 1989;28(1):97-104.

70. Yoshimura R, Nakamura J, Ueda N, Terao T. Effect of risperidone on plasma free 3-methoxy-4-hydroxyphenylglycol (pMHPG) levels in schizophrenic patients: relationship among plasma concentrations of risperidone and 9-hydroxyrisperidone, pMHPG levels, and clinical improvement. Int Clin Psychopharmacol. 2000;15(3):175-180.

71. Yoshimura R, Ueda N, Shinkai K, Nakamura J. Plasma levels of homovanillic acid and the response to risperidone in first episode untreated acute schizophrenia. Int Clin Psychopharmacol. 2003;18(2):107-111.

72. Grace AA, Bunney BS, Moore H, Todd CL. Dopamine-cell depolarization block as a model for the therapeutic actions of antipsychotic drugs. Trends Neurosci. 2017;20(1):31-37.

73. Davila R, Manero E, Zumarraga M, Andia I, Schweitzer JW, Friedhoff AJ. Plasma homovanillic acid as a predictor of response to neuroleptics. Arch Gen Psychiatry. 1988;45(6):564-567.

74. Bowers MBJ, Swigar ME, Jatlow PI, Goicoechea N. Plasma catecholamine metabolites and early response to haloperidol. J Clin Psychiatry. 1984;45(6):248-251.

75. Chang WH, Chen TY, Lee CF, Hung JC, Hu WH, Yeh EK. Plasma homovanillic acid levels and subtyping of schizophrenia. Psychiatry Res. 1988;23(3):239-244.
76. Davidson M, Kahn RS, Knott P, et al. Effects of neuroleptic treatment on symptoms of schizophrenia and plasma homovanillic acid concentrations. Arch Gen Psychiatry. 1991;48(10):910-913.

77. van Putten T, Marder SR, Aravagiri M, Chabert N, Mintz J. Plasma homovanillic acid as a predictor of response to fluphenazine treatment. Psychopharmacol Bull. 1989;25(1):89-91.

78. Vernaleken I, Kumakura Y, Buchholz HG, et al. Baseline $\left[{ }^{18} \mathrm{~F}\right]-F D O P A$ kinetics are predictive of haloperidol-induced changes in dopamine turnover and cognitive performance: a positron emission tomography study in healthy subjects. Neuroimage. 2008;40(3):1222-1231.

79. de Bartolomeis A, Tomasetti C, Iasevoli F. Update on the mechanism of action of aripiprazole: translational insights into antipsychotic strategies beyond dopamine receptor antagonism. CNS Drugs. 2015;29(9): 773-799.

80. Jordan S, Koprivica V, Dunn R, Tottori K, Kikuchi T, Altar CA. In vivo effects of aripiprazole on cortical and striatal dopaminergic and serotonergic function. Eur J Pharmacol. 2004;483(1):45-53.

81. Kikuchi T, Tottori K, Uwahodo Y, et al. 7-(4-[4-(2,3-Dichlorophenyl)1-piperazinyl]butyloxy)-3,4-dihydro-2(1H)-quinolinone (OPC-14597), a new putative antipsychotic drug with both presynaptic dopamine autoreceptor agonistic activity and postsynaptic D2 receptor antagonistic activity. J Pharmacol Exp Ther. 1995;274(1):329-336.

82. Koener B, Focant MC, Bosier B, Maloteaux JM, Hermans E. Increasing the density of the $\mathrm{D} 2 \mathrm{~L}$ receptor and manipulating the receptor environment are required to evidence the partial agonist properties of aripiprazole. Prog Neuropsychopharmacol Biol Psychiatry. 2012;36(1): 60-70.

83. Ma GF, Raivio N, Sabría J, Ortiz J. Agonist and antagonist effects of aripiprazole on $\mathrm{D}_{2}$-like receptors controlling rat brain dopamine synthesis depend on the dopaminergic tone. Int J Neuropsychopharmacol. 2014;18(4):pyu046.

84. Friedhoff AJ. A dopamine-dependent restitutive system for the maintenance of mental normalcy. Ann N Y Acad Sci. 1986;463:47-52.

85. Kaminski R, Powchick P, Warne PA, Goldstein M, McQueeney RT, Davidson M. Measurement of plasma homovanillic acid concentrations in schizophrenic patients. Prog Neuropsychopharmacol Biol Psychiatry. 1990;14(3):271-287.

86. Suzuki E, Kanba S, Nibuya M, et al. Longitudinal changes in symptoms and plasma homovanillic acid levels in chronically medicated schizophrenic patients. Biol Psychiatry. 1994;36(10):654-661.

87. Ribeyre JM, Lesieur P, Varoquaux O, Dollfus S, Pays M, Petit M. A comparison of plasma homovanillic acid in the deficit and nondeficit subtypes of schizophrenia. Biol Psychiatry. 1994;36(4):230-236.

88. Zhang ZJ, Peet M, Ramchand CN, Shah S, Reynolds GP. Plasma homovanillic acid in untreated schizophrenia: relationship with symptomatology and sex. J Psychiatr Res. 2001;35(1):23-28.

89. Beuger M, van Kammen DP, Kelley ME, Yao J. Dopamine turnover in schizophrenia before and after haloperidol withdrawal: CSF, plasma, and urine studies. Neuropsychopharmacology. 1996;15(1):75-86.

90. Ramirez-Bermudez J, Ruiz-Chow A, Perez-Neri I, et al. Cerebrospinal fluid homovanillic acid is correlated to psychotic features in neurological patients with delirium. Gen Hosp Psychiatry. 2008;30(4):337-343.

91. van der Cammen TJ, Tiemeier H, Engelhart MJ, Fekkes D. Abnormal neurotransmitter metabolite levels in Alzheimer patients with a delirium. Int J Geriatr Psychiatry. 2006;21(9):838-843.

92. Fervaha G, Takeuchi H, Lee J, et al. Antipsychotics and amotivation. Neuropsychopharmacology. 2015;40(6):1539-1548.

93. Naber D, Karow A, Lambert M. Subjective well-being under the neuroleptic treatment and its relevance for compliance. Acta Psychiatr Scand Suppl. 2005;(427):29-34.

94. Nuss P, Tessier C. Antipsychotic medication, functional outcome and quality of life in schizophrenia: focus on amisulpride. Curr Med Res Opin. 2010;26(4):787-801.

95. Schennach-Wolff R, Seemüller F, Obermeier M, et al. Response and remission of subjective well-being in patients suffering from schizophrenia spectrum disorders. Eur Psychiatry. 2011;26(5):284-292. 
96. deHaanL, van Bruggen M, Lavalaye J, Booij J, Dingemans PM, LinszenD. Subjective experience and D2 receptor occupancy in patients with recent-onset schizophrenia treated with low-dose olanzapine or haloperidol: a randomized, double-blind study. Am J Psychiatry. 2003;160(2): 303-309.

97. Lataster J, van Os J, de Haan L, et al. Emotional experience and estimates of D2 receptor occupancy in psychotic patients treated with haloperidol, risperidone, or olanzapine: an experience sampling study. J Clin Psychiatry. 2011;72(10):1397-1404.

98. Mizrahi R, Rusjan P, Agid O, et al. Adverse subjective experience with antipsychotics and its relationship to striatal and extrastriatal D2 receptors: a PET study in schizophrenia. Am J Psychiatry. 2007;164(4): 630-637.

99. Mizrahi R, Mamo D, Rusjan P, Graff A, Houle S, Kapur S. The relationship between subjective well-being and dopamine D2 receptors in patients treated with a dopamine partial agonist and full antagonist antipsychotics. Int J Neuropsychopharmacol. 2009;12(5):715-721.

100. Castanho TC, Moreira PS, Portugal-Nunes C, et al. The role of sex and sex-related hormones in cognition, mood and well-being in older men and women. Biol Psychol. 2014;103:158-166.

101. Henry JF, Sherwin BB. Hormones and cognitive functioning during late pregnancy and postpartum: a longitudinal study. Behav Neurosci. 2012;126(1):73-85.

102. Slopien R, Slopien A, Warenik-Szymankiewicz A. Serum prolactin concentration and severity of depression symptoms in climacteric women. Clin Exp Obstet Gynecol. 2015;42(6):749-751.

103. Montalvo I, Gutierrez-Zotes A, Creus M, et al. Increased prolactin levels are associated with impaired processing speed in subjects with early psychosis. PLoS One. 2014;9(2):e89428

104. Lee BJ, Lee SJ, Kim MK, et al. Effect of aripiprazole on cognitive function and hyperprolactinemia in patients with schizophrenia treated with risperidone. Clin Psychopharmacol Neurosci. 2013;11(2): 60-66.
105. Gianfrancesco FD, Pandina G, Mahmoud R, Wu J, Wang RH. Potential bias in testing for hyperprolactinemia and pituitary tumors in risperidone-treated patients: a claims-based study. Ann Gen Psychiatry. 2009;8:5.

106. Peuskens J, Pani L, Detraux J, de Hert M. The effects of novel and newly approved antipsychotics on serum prolactin levels: a comprehensive review. CNS Drugs. 2014;28(5):421-453.

107. Haddad PM, Wieck A. Antipsychotic-induced hyperprolactinaemia: mechanisms, clinical features and management. Drugs. 2004;64(20): 2291-2314.

108. Holt RI. Medical causes and consequences of hyperprolactinaemia: a context for psychiatrists. J Psychopharmacol. 2008;22(2 Suppl): 28-37.

109. Nagaoka S, Iwamoto N, Arai H. First-episode neuroleptic-free schizophrenics: concentrations of monoamines and their metabolites in plasma and their correlations with clinical responses to haloperidol treatment. Biol Psychiatry. 1997;41(8):857-864.

110. Umene W, Yoshimura R, Hori H, et al. Blood levels of catecholamine metabolites and brain-derived neurotrophic factor in a case of Sydenham's chorea. World J Biol Psychiatry. 2009;10(3):248-251.

111. Steinberg JL, Garver DL, Moeller FG, Raese JD, Orsulak PJ. Serum homovanillic acid levels in schizophrenic patients and normal control subjects. Psychiatry Res. 1993;48(2):93-106.

112. Lehrl S, Triebig G, Fischer B. Multiple choice vocabulary test MWT as a valid and short test to estimate premorbid intelligence. Acta neurologica Scandinavica. 1995;91(5):335-345.

113. Gupta RN, Whelton C. Determination of plasma homovanillic acid by liquid chromatography with electrochemical detection. J Chromatogr. 1992;582(1-2):236-241.
Neuropsychiatric Disease and Treatment

\section{Publish your work in this journal}

Neuropsychiatric Disease and Treatment is an international, peerreviewed journal of clinical therapeutics and pharmacology focusing on concise rapid reporting of clinical or pre-clinical studies on a range of neuropsychiatric and neurological disorders. This journal is indexed on PubMed Central, the 'PsycINFO' database and CAS,

\section{Dovepress}

and is the official journal of The International Neuropsychiatric Association (INA). The manuscript management system is completely online and includes a very quick and fair peer-review system, which is all easy to use. Visit http://www.dovepress.com/testimonials.php to read real quotes from published authors. 